\title{
How the meanings of 'home' influence energy-consuming practices in domestic buildings
}

\author{
Xinfang Wang (D) Dana Abi Ghanem • Alice Larkin • \\ Carly McLachlan
}

Received: 12 June 2018 / Accepted: 18 November 2020 /Published online: 5 December 2020

(C) The Author(s) 2020

\begin{abstract}
The UK introduced carbon budgets in 2008, with an aim to reduce greenhouse gases by $80 \%$ by 2050 compared with the 1990 levels. It has been argued that the 2015 Paris Agreement on limiting the global average temperature rise to 'well below $2^{\circ} \mathrm{C}$ ' requires deeper and more rapid emission reductions than the current UK targets. Household energy consumption accounts for almost a third of total $\mathrm{UK} \mathrm{CO}_{2}$ emissions in recent years. This paper explores drivers of high energy consumption in domestic buildings from a sociological practice perspective and through a lens of dominant meanings of 'home'. Whilst the practice approach and meanings of home have been explored separately in the literature to understand household energy consumption, this paper adds new findings on the interaction between the meanings of home and the elements of practices. Results show the dominant meaning of home differs between householders; this in turn affects the materials and procedures of energy-consuming practices. For instance, if
\end{abstract}

\footnotetext{
X. Wang $(\bowtie)$

School of Chemical Engineering, University of Birmingham, Edgbaston, Birmingham, UK

e-mail: x.wang.10@bham.ac.uk

D. A. Ghanem

Centre for Sustainable Engineering, School of Computing, Engineering and Digital Technologies, Teesside University, Middlesbrough, UK

\section{A. Larkin - C. McLachlan}

Tyndall Centre for Climate Change Research, School of Engineering, Department of Mechanical, Aerospace and Civil Engineering, University of Manchester, Manchester, UK
}

'home' means 'hospitality', this changes the standard of comfort and convenience people perceive at home. Understanding how practices and meanings of the home intersect, provides new, much needed insights that could support policy change commensurate with more rapidly reducing $\mathrm{CO}_{2}$ emissions from domestic energy consumption.

Keywords Household energy consumption · Energy demand reduction policy $\cdot$ Energy efficiency $\cdot$ Meanings of home $\cdot$ Practice theory $\cdot$ Accelerating emissions reductions

\section{Introduction: energy consumption, home and practices $^{1}$}

A focus on reducing and decarbonising household energy use has increased in many countries since the Intergovernmental Panel on Climate Change (IPCC) First Assessment Report was published in 1990, in order to achieve global climate change mitigation and adaptation (IPCC 1990). The UK Government became the first to put an emission reduction target into statute in 2008 when it committed to reduce its greenhouse gas (GHG) emissions by at least $80 \%$ by 2050 , compared to the 1990 baseline (Climate Change Act 2008). This target was premised on a $63 \%$ probability of exceeding a $2^{\circ} \mathrm{C}$ global temperature rise (Committee on Climate Change

\footnotetext{
${ }^{1}$ A practice is what people do, such as eating, playing, walking and sleeping (Shove et al. 2012; Gram-Hanssen 2014). A fuller explanation is given in Section 3.
} 
2008), in contrast to the 2015 Paris Agreement that aims to limit the global average temperature rise to 'well below $2^{\circ} \mathrm{C}$ ' (United Nations 2015). It has been argued therefore that the Paris Agreement requires deeper and more rapid emission reductions than the current UK targets (Anderson 2015; Committee on Climate Change 2016; Pye et al. 2017) because the more emissions are released into the atmosphere in the short term, thereby accumulating, the more difficult it will be to meet the Agreement goal given the rate of reductions that will become necessary later on (Anderson and Bows 2011). In June 2019, the UK passed further legislation for reaching 'Net Zero' GHG emissions by 2050 (HM Government 2019). The $\mathrm{CO}_{2}$ emissions from household energy use accounted for around $27 \%$ of total territorial-based $\mathrm{CO}_{2}$ emissions in the UK by end-users in 2016; the remaining $\mathrm{CO}_{2}$ emissions are mainly due to the business/industry (30\%) and transport (36\%) sectors (BEIS 2018a).

The $\mathrm{CO}_{2}$ emissions from the UK household energy use were 101.4 million tonnes (Mt) in 2016, having decreased by 35\% compared with 1990 levels (BEIS 2018a). The switch from solid fuel to gas for UK electricity generation, and the reduced use of solid fuel at home, made key contributions to decreasing UK household $\mathrm{CO}_{2}$ emissions (DECC 2013b; Nejat et al. 2015). In spite of the $35 \%$ reduction of $\mathrm{CO}_{2}$ emissions from this sector, the total household energy consumption in the UK increased by $1 \%$ between 1990 and 2016 (BEIS 2017). This suggests that, notwithstanding numerous efforts over the years (outlined in the "Policies for reducing household energy consumption in the UK" section), more is needed to reduce energy use in domestic buildings. Furthermore, in order to ensure that policy efforts are effective at achieving emission reduction targets in the UK, it is important to improve our understanding of how and why people use energy at home, and what in particular leads to high or low levels of $\mathrm{CO}_{2}$ emissions.

Studies on residential energy use and carbon emissions from a social science perspective have been dominated by behaviour change approaches that focus on people's attitudes and individual actions (GramHanssen 2014). This dominant approach has been critiqued from a sociological perspective (Shove 2010, 2017), particularly for the way an emphasis on removing barriers to change individual behaviours alone may limit broader significant societal transformations required to move to a decarbonised economy. A practice approach has been called upon to be applied in carbon mitigation policy-making, focusing on which routines and lifestyles - or simply stated 'what people do' (Shove 2010) — could lead to high energy consumption in domestic buildings. Regarding the domestic sector, literature on energy use has similarly argued the importance of looking beyond the built environment attributes (Guy 2006; Crosbie and Guy 2008) and instead to consider energy consumption from a socio-technical perspective where the interrelationships between the mundane elements of people's lives and daily routines alongside the material attributes of the built environment facilitate or constrain energy consumption (Guy and Shove 2000). Since this socio-technical turn in energy studies, research has explored the adoption of new energy innovations such as smart home technologies (Wilson et al. 2017), energy-efficient heating systems (Rinkinen and Jalas 2017), demand side management interventions and the uptake of insulation measures for homes (Foulds and Powell 2014; Pettifor et al. 2015).

The meanings of home have been considered in relation to energy conservation by Aune (2007) and Aune et al. (2016), and with regard to smart energy interventions by Gram-Hanssen and Darby (2018). These insights point to the importance of exploring the meaning of the home when considering $\mathrm{CO}_{2}$ emission reductions in the domestic sector, where research has attested to the social meanings attributed to homes and how these are continually created and recreated in householders' practices (Després 1991; Blunt and Dowling 2006; Aune 2007; Gram-Hanssen and Darby 2018). This paper follows in this tradition by delineating the meaning of home in addition to exploring the various practices householders participate in, so that a better understanding of energy use and the potential for carbon reduction in this sector is achieved.

The research presented in this paper builds on earlier work by Lutzenhiser (1992: 55), which called for an appreciation of the cultural and anthropological meaning of 'houses, automobiles and appliances.' Similarly, research on domestic energy consumption has argued that houses and the notion of home, as well as appliances, are meaningful in family life and social networks (Aune 2007; Ellsworth-Krebs et al. 2015) and have argued for an energy research agenda centred on the social aspects of home and their influence on everyday energy consumption, whilst Aune (2007) and Madsen (2017) have explored the notion of 'comfortable home' in relation to energy use. 
Going beyond the notion of comfort, the aim of this paper is to examine how people perceive and use their home through a qualitative exploration of energy consumption alongside a systematic break-down of how the uses of the home have affected the energy-intensiveness of social practices. In this paper, empirical work is carried out to contribute to understanding the reasons behind high energy consumption in domestic buildings through integrating the two different perspectives - the social practice approach and meanings of home, as prioritised by their inhabitants. Implications for energy policy and the design of new technologies (e.g. technologies for smart homes or smart appliances) are provided to suggest ways for reducing energy consumption, based on this paper's findings on how people's practices intersect with prioritised meanings of home. Whilst the paper does not seek to develop the theories themselves, it presents an examination of what each perspective provides, how they intersect and how it could be useful to integrate the two perspectives to understand energy consumption. Combining both perspectives is inspired by Guy and Moore's (2007) 'pluralism' approach for addressing sustainability in the built environment, where the diversity of disciplines and insights in relation to energy and buildings is welcomed.

The remainder of this paper is structured as follows. The next section introduces policies for reducing household energy consumption in the UK. The 'Theoretical approach' section explains the practice approach and the meanings of home perspectives in detail, as well as the framework applied in this paper. Data collection methods are presented in the 'Data collection methods' section, with results shown in the 'Analysis and findings' section. The 'Discussion' section comprises indepth discussions of implications for policies and smart home technologies. The final section concludes with the key contributions of the paper.

\section{Policies for reducing household energy consumption in the UK}

The UK has initiated various policies that focus on household energy consumption. In relation to appliances, the UK Government published the Energy Information Regulations 2011/1524, which requires labelling energy and other resource consumption information on all energy-related products. Despite its launch, it is argued that householders may not adopt more energy- efficient products as these may be more expensive than other less efficient ones or they may not fit the home design (Crosbie and Guy 2008). For energy efficiency of buildings, the UK regulation Building and Buildings, England and Wales 2007/991 requires the seller or landlord to order an Energy Performance Certificate (EPC) whenever a property is sold, rented or built in England and Wales. The EPC contains information about the property's current energy use and average energy price, as well as an estimate of the potential energy efficiency improvements if efficiency measures (e.g. loft and cavity wall insulation) are installed. A minimum EPC rating of E is required since April 2018 for private rented properties (Energy Conservation, England and Wales 2015); however, this still represents a relatively low level of energy efficiency, which may not lead to significantly better-insulated properties.

Previously, in an effort to improve energy efficiency of existing homes in Great Britain, the Energy Efficiency Commitment (EEC) was initiated in 2002, which required energy suppliers to invest in the energy efficiency of their customers' dwellings and achieve the suppliers' energy efficiency improvement targets through households (Lees 2008). The EEC was subsequently replaced by the Carbon Emission Reduction Target (CERT), which ran between April 2008 and December 2012. In addition, the Community Energy Savings Programme (CESP) was established in 2009 to complement the CERT, with a focus on incomedeprived $^{2}$ households. However, both CERT and CESP schemes were later replaced by the Green Deal and the Energy Company Obligation (ECO) (DECC 2010; Foulds and Powell 2014; BEIS 2018b).

The Green Deal was launched in January 2013 to improve energy efficiency in residential buildings (DECC 2010; Foulds and Powell 2014), and consists of the following four stages: (i) a home assessment by professional assessors; (ii) finance for the agreed installation scheme; (iii) installation of the agreed systems; and (iv) repayment from the saved energy bills. Its uptake was low, possibility due to householders' aversion to delayed gains, lack of trust in contractors or access to information, complexity and uncertainties of

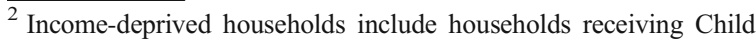
Benefit, Jobseeker's Allowance, Pension Credit, Child Tax Credit, and those with equivalised Before Housing Cost income (total household income after taxes and benefits) below $60 \%$ of the median level in the UK (Department of Communities and Local Government (DCLG) 2011).
} 
future financial benefits, lack of awareness, and disruption during the installation stage (Pettifor et al. 2015). In addition, it is argued that the Green Deal adopters may lose out financially in terms of resale price if they move out before the end of the Green Deal payback period, because fixed loan repayments attached to the dwelling can discourage potential homebuyers (Bachelor 2013; Balcombe et al. 2014).

A household's engagement with the Green Deal could also be influenced by their house renovation plans, as identified by Pettifor et al. (2015), whereby the Green Deal programme increased awareness of energy efficiency among householders who were already thinking of renovating their homes. However, the narrow focus of the programme on energy performance and savings on energy bills was insufficient to increase the uptake of broader energy efficiency measures (Pettifor et al. 2015). Other householders' non-financial considerations, such as improving aesthetics and comfort of their homes are also important (Haines and Mitchell 2014).

The Green Deal Home Improvement Fund (GDHIF) was released in June 2014 to implement the Green Deal, providing up to $£ 7600$ cash back for households towards their energy efficiency installations (DECC 2015a). By the end of October 2015, there were 37,489 energy efficiency measures installed under the GDHIF with a total value of approximately $£ 145.4$ million (DECC 2015a). Nonetheless, on 23 July 2015, the UK Government announced that no further funding to the GDHIF was available (DECC 2015a), citing low uptake as one reason for halting the programme. For households who have already taken part, there was uncertainty of the savings they could achieve as that depended on their usage patterns and direct rebound effects, where people would spend the money saved on energy bills-from improved energy efficiency or behaviour change - on other energy services, such as lighting or space heating, resulting in more energy consumption (Sorrell and Dimitropoulos 2008; Chitnis et al. 2014). For example, some people may leave more lights on after changing to energy-efficient bulbs, or they may increase their indoor temperature after insulation.

Along with the Green Deal, the ECO was also launched in 2013 to provide additional support especially for vulnerable households and hard-to-treat homes (The Electricity and Gas (Energy Companies Obligation) (Amendment) Order 2014). The latest ECO runs until March 2022 (BEIS 2018b) and places legal obligations on energy suppliers to deliver energy efficiency measures to residential energy users. There are three different obligations including the Affordable Warmth Obligation, Carbon Saving Obligation and Carbon Saving Communities Obligation. The Affordable Warmth Obligation targets low-income and vulnerable households, and is a replacement for the Warm Front Scheme launched in England in 2000. The latter was aimed at helping low-income households and households in fuel poverty with energy efficiency improvements, although $75 \%$ of qualified households for this scheme were not in fuel poverty (DECC 2013a).

For rented residential properties, the Landlord's Energy Saving Allowance (LESA) was implemented between April 2004 and April 2015, which provided grants to landlords for upfront payments on energy efficiency measures, including various types of insulation (HM Revenue and Customs 2016). The scheme initially allowed a maximum of $£ 1500$ per building between April 2004 and April 2007, and was changed to $£ 1500$ per dwelling after that. However, the LESA was not widely known, and it was difficult to identify the rented properties, leading to low participation (Boardman 2007).

In addition to improving energy efficiency, policies in the UK also focused on providing more information on energy and $\mathrm{CO}_{2}$ emissions to householders. The smart metre rollout scheme was identified as a possible energy-saving measure in the UK 2007 White Paper on Energy (Department for Trade and Industry 2007). Smart metres can display and provide real-time information on gas and electricity consumption to energy suppliers and consumers, as well as metering exports from renewable micro-generators. Through the In Home Display provided by energy suppliers, consumers are able to learn about the amount and cost of their energy consumption, arguably enabling them to better control and manage it (DECC 2015c). Other than information provision, policymakers also focused on changing consumers' attitudes and behaviours through various campaigns (Collins et al. 2003; Capstick et al. 2014), such as the 1998 'Are you doing your bit (AYDYB)', the 2000 'Do a little, change a lot' campaign and the 'Big Energy Saving Week' started in 2016. These campaigns improved people's knowledge of energy use at home, making more households aware of the energy expenditure from standby electric appliances (Collins et al. 2003). However, it was also acknowledged that knowledge and attitudes do not necessarily lead to energy- 
saving behaviours (information-behaviour gap) (O'Brien 2012), and that advertising campaigns needed to be part of a wider package of policy measures rather than working in isolation.

\section{Theoretical approach}

A practice approach to understanding energy consumption

A practice approach to understanding energy consumption has gained traction in recent years as researchers moved away from individualistic explanations of actions, such as their attitudes and values, into social explanations where the activity itself is the focus of study. At present, there is a broad range of literature that explores consumption through a practice approach (Southerton 2013; Sahakian and Wilhite 2014; Warde $2005,2014)$, and this paper draws on work that focuses on energy use at home. Shove and Pantzar's (2005) outlined practices - what people do-as constituting three main elements: (i) materials (i.e. physical objects and infrastructure), (ii) meanings (i.e. images and interpretations) and (iii) competences (i.e. skills, knowledge and habits) (Shove and Pantzar 2005). Whilst several theorists and researchers on practices and consumption have interpreted and grouped these elements slightly differently (Gram-Hanssen 2011; Reckwitz 2002; Warde 2005), the outline by Darnton et al. (2011) is adopted in this paper to identify areas for policy implications and the design of new technologies for reducing energy consumption. Darnton et al. (2011) referred to competences as 'procedures' which additionally refer to 'frameworks' and 'schedules'; the former relates to legislation or regulations and 'schedules' refer to weather, time and daily routines. The three elements - materials, procedures and meanings - together constitute practices, whereby the form, frequency and time it takes to perform a practice rely on the materials and technologies involved in that practice and the competences or skills and knowledge required to do it. The capacity of practices to entice or recruit practitioners into a practice depends on the various meanings associated with it. Taking laundry practice as an example, the materials consist of the clothing, the washing machine and detergents, whilst when and how the washing is done (e.g. separation of colours or different cycles for various fabrics) relates to competences and procedures, and why it is done pertains to the various meanings associated with washing clothes including notions of freshness or cleanliness. The different elements - materials, procedures and meanings - hold together to shape the performance of laundry as a practice. Linking practices with household energy consumption, Fig. 1 shows examples under each element of a practice. Seen this way, the practice approach offers an alternative understanding to individualistic explanations of why and how energy-consuming activities occur, and provides ways for unpacking the elements of practices that constitute daily routines.

Whilst the focus on practices is perceived by proponents of the behavioural approach to be addressed by looking at the 'context', such as the attitude-behaviourchoice (ABC) model (Stern 2000), Shove's (2010) argument is that this is provided ultimately to remove the barriers of behaviour change and provide people with more choices, rather than examining the practices themselves. Importantly, the focus on behaviours has informed many of the policies aimed at behavioural change, some of which have been discussed in the 'Policies for reducing household energy consumption in the UK" section, with the result that they do not address elements of practices as a whole and the unmotivated reproduction of practices in daily routines (Darnton et al. 2011).

The elements of practices not only hold together and constitute these practices but also lead to variations, and householders can differ in their normal everyday

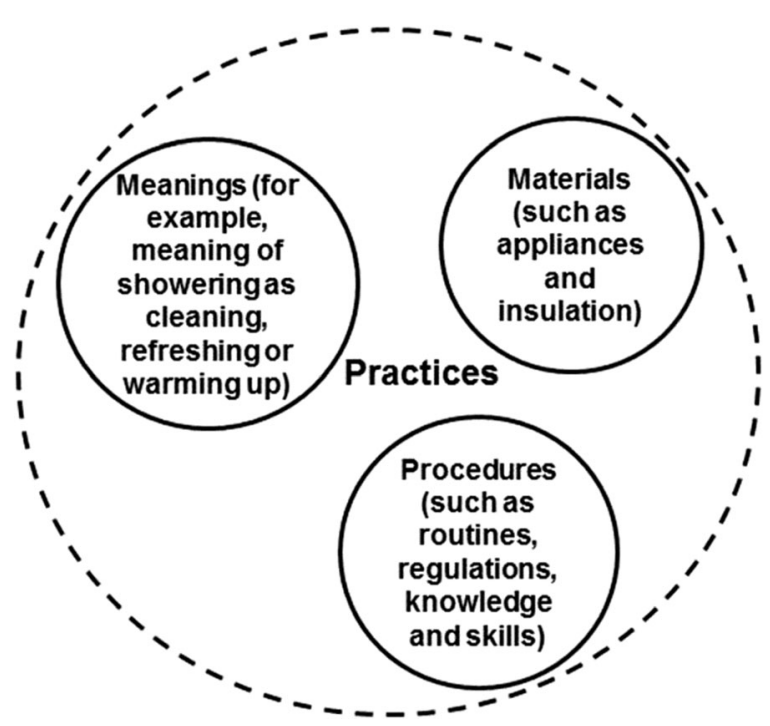

Fig. 1 Adapted from the three-element practice approach in Shove and Pantzar (2005) and Darnton et al. (2011) 
practices due to the technology available, embodied habits, skills and interests (Gram-Hanssen 2011). For example, leaving the lights on in unoccupied rooms can mean a homely atmosphere that is important to some people but not to others, which implies that the performance of practices can be different even between households with similar socioeconomic factors, materials and competences. Elsewhere, Rinkinen and Jalas (2017) explored the formation and variation in home-heating practices when people moved into new homes. These instances provided moments in people's lives where new arrangements of materials (existing or new heating systems), competences (news skills required) and meanings (ideas of proper living) came together, leading to radical changes within homes and subsequently their energy use. As such, the notion of the house or home as a complex set of material arrangements that influence the formation and variation of practice is raised.

\section{Prioritised meanings of the home}

There are differences between 'home' and 'house'; the home is more than a physical object as it is connected to feelings and relationships (Ellsworth-Krebs et al. 2015; Gram-Hanssen and Darby 2018). Després (1991) outlined the meaning of 'home' from different theoretical perspectives, presenting a territorial model, psychological model and social psychological model. A sociological perspective is applied in this paper presented here. Whilst certain notions relate to specific everyday practices, the prioritised meanings of home go beyond that to consider a broader perspective that perceives the main functions of the home as a whole. As such, the meaning of home is conceptualised on a different scale from the meaning of practices, and so have different implications for the design of specific policy instruments or the development of home energy innovations.

Aune (2007) explored opportunities for reducing energy use at home through the perspective of 'meanings of the home' in research that analysed energy expenditure in relation to everyday life and the use of energy controlling technology (Aune 2002; Aune et al. 2016). Her work presented three meanings of home which are as follows: (i) home as a continuous project, where households may renovate or refurbish the home more frequently than others; (ii) home is a haven of comfort, where comfort may be pursued through indoor temperature, space size, furniture or lighting; and (iii) home as a place for performing activities in everyday life, such as washing, cooking and other family activities. These three meanings are not exclusive, but householders may prioritise one over the others at different points in their lives (Aune 2007). As such, households that prioritise home as a continuous project are more likely to change their appliances and insulation through rebuilding and refurbishing; households that prioritise home as a haven focus more on the comfort, unity and privacy of the home, whereas households that prioritise home as an area for activities are likely to respond the most to increasing energy prices and information for saving energy bills (Aune 2007). More recently, GramHanssen and Darby (2018) explored the concepts of home focusing on the role of smart home technologies, where the home is a place for (i) security and control, (ii) activity, (iii) relationships and continuity, and (iv) identity and values. Like Aune (2007), Gram-Hanssen and Darby (2018) also emphasised that the different categories in no way exclude each other, but are distinguished for structuring the analysis according to their research objective.

In addition to the meanings identified above (Aune 2007; Gram-Hanssen and Darby 2018), the use of home for hospitality has also been previously identified as an influence on how people use energy for space heating/ cooling to ensure guests' comfort (Wilhite and Ling 1992; Agbemabiese et al. 1996; Wilhite et al. 1996; Strengers and Maller 2011). Prioritising home for guests' use is different from prioritising home for internal family members' activities, because in order to ensure guests enjoy their stay, some people could provide extra space heating (e.g. increasing room temperature), lighting (e.g. more left-on lights in the hall and other shared space), cooking (e.g. extra diversity of cooked food) and entertainment (e.g. having TV or music left on), which they may not usually do. In a study by Wilhite and Ling (1992) in Norway, it was found that if guests in a home gave any signs of being cold, that would be considered a 'serious disgrace' to the host. In addition to overheating, over-lighting has also been perceived necessary due to the strong social significance of cosiness when guests enter (Wilhite et al. 1996). Likewise, Strengers and Maller (2011) noted that women in Australia are more sensitive than men to their guests' comfort and would leave the air conditioner on when having guests at home. 
Framework based on a practice approach and prioritised meanings of the home

Despite both the notion of meanings of home and practice theory as a body of work having been applied separately to explore energy consumption and carbon emissions in UK homes, there has been few empirical studies synthesising insights from both perspectives to explore whether and how they interconnect, and if a framework that combines insights from both can shed new light on the design of policies or technologies aimed at energy consumption and carbon emissions reductions.

In this paper, practices that shape people's everyday lives are analysed, rather than isolated energy behaviours. Taking lighting practice as an example, the act of leaving the light on whilst away from home is not simply understood as an individual behaviour, but as related to the energy efficiency of the light bulbs (materials of the practice), householders' broader habits (procedures of the practice), concern for safety with the aim of avoiding burglars targeting their home and leaving the lights on to create the welcoming atmosphere for householders when arriving home (meanings of the practice). As such, this research explores variations in energyconsuming practices to understand why some people use more energy at home than others, by considering household practices over time and the various and prioritised meanings people have of their dwelling.

The home itself can be understood as a homemaking practice, where the term 'practice' refers to things people do to render their accommodation homely (Mallett 2004; Madsen 2017; Gram-Hanssen and Darby 2018). It is important to clarify here that this paper does not interpret home as a practice, but rather, the concept of practice is used to refer specifically to things people do at home that require energy, and a 'home' is understood as the space that can be associated with the feelings and relationships of people, and therefore differentiating the meanings of home from the meanings of energy-consuming practices. This paper explores the 'meanings' of energyconsuming practices that emerged from the empirical work, and further explores and discusses whether and how the meanings of home have changed the elements (materials, procedures and meanings) of energy-consuming practices, potentially leading to significant levels of energy use at home.

\section{Data collection methods}

Data was collected using semi-structured interviews conducted with 25 selected households within the Greater Manchester area in the UK between June and August 2015. The research participant selection strategy aimed to cover various household compositions, income levels and a range of monthly gas and electricity bills to explore how energy use differs across various types of households. Potential interviewees were invited by email, through contacts from colleagues in the University where the researcher was located. Based on gaps in income and energy bill levels among those already recruited through these strategies, selected neighbourhoods within and around the Greater Manchester area were also leafleted, until the targeted type and number of households were recruited. Posters were also put up in community centres, local libraries and amenities around the targeted neighbourhoods for the same purpose.

To ensure that the interviews would collect as much detailed data as possible on how householders perform practices at home that may link to high levels of energy consumption, guided questions were used that covered household members, materials (such as appliances, insulation and size of the dwelling), goals to achieve at home and routines of each household member in a typical weekday and weekend. Due to safety concerns around conducting interviews in private locations that were raised by the authors' University's Committee of the Ethics of Research on Human Beings, interviews were not conducted in participants' homes but in public locations instead, such as cafes or meeting rooms in local libraries. To overcome this limitation, participants were asked to take photos of each room of their homes, which were used during the interviews to remind them when, where, how and by whom their repeated daily activities at home take place. To explore more of how the home is being used, participants were asked to describe how and when each room was used and by whom. They were also requested to summarise their main activities at home, which room they spend most time in, what they like most and least about their home and what they most look forward to when coming home. In addition, the interviewees were asked to list the appliances they have in each room, describing what the appliances are used for, how often, whether anything is left on and, if so, for what reason. They were also asked whether they had done any renovation or 
refurbishment, whether they had replaced any appliance or added new appliances, and, if so, why. The guided questions helped to ensure that the interviewees talked about the various everyday activities associated with the uses of their homes.

Although the semi-structured interviews focused on energy use, respondents were asked to emphasise important issues through their own experiences and elicit their opinions. This allowed the interviewer to identify new emerging themes related to household practices. Interviews took approximately $90 \mathrm{~min}$ on average. Due to the nature of qualitative research, the number of interviewees was decided by using the saturation sampling principle, rather than statistical sampling, where data collection continues until new themes no longer emerge, and no substantial data collected can add to the themes that have already emerged (Morse and Richards 2002). The interviews were transcribed verbatim and anonymised to protect interviewees' identities.

The data was analysed to identify similarities and differences in various home-based energy-consuming practices across households. Thematic analysis (Attride-Stirling 2001) was used based on practice theory. The process involved identifying several relevant themes that were coded using the qualitative data analysis software Atlas.ti. The list of themes was then continuously modified and updated leading to the final themes that emerged. These were further categorised and analysed to explore how they influence energyrelated practices at home, individually or collectively, affecting overall energy consumption and $\mathrm{CO}_{2}$ emissions.

In addition, the self-reported disposable income $\mathrm{e}^{3}$ and energy bills for each participating household are presented in Table 1. Both the income level and energy bill are equivalised according to household composition for comparison, due to the influence from economies of scale on household consumption. Household income is equivalised using the modified Organisation for Economic Co-operation and Development (OECD) Equivalence Scale (Table 2), whereas household energy bills were equivalised using the Low Income High Cost (LIHC) equivalisation factors (Table 3), to be consistent with the former Department for Energy and Climate Change (DECC) (2014) who used the same factors to

\footnotetext{
${ }_{3}^{3}$ Disposable income is defined as gross income after taxes and benefits (ONS 2006).
}

equivalise household energy bills in the fuel poverty calculation. The distribution of equivalised household income and energy bills for all participating households is presented in Fig. 2. The interviewees are selected from households with equivalised monthly disposable income between $£ 0$ and $£ 2333$, and equivalised monthly gas and electricity bills between $£ 38$ and $£ 148$ (Table 3 ). Figure 2 shows that there is no clear correlation between their equivalised disposable incomes and the equivalised gas and electricity bills, which supports the paper's argument that understanding how energy use is embedded in everyday practices and prioritised meanings of home is highly essential.

It is important to note that there is self-reported data bias in most qualitative data collection methods (Mullaly 1998). In this research, the self-reported data bias may be caused by the respondents recalling how they have performed the practices in their everyday lives, or they may consciously under or over report their energy bills, income or daily activities if they try to provide more socially approved answers rather than actual data (Warriner et al. 1984). Warriner et al. (1984) examined the accuracies of self-reported data on household energy consumption among approximately 1500 consumers in Canada, through comparing the self-reported data with the data recorded by their energy suppliers. Results showed that the bias of self-reported data ranges between \pm 10.5 and $\pm 29.3 \%$ depending on whether the respondents reported data through estimate or self-kept records such as energy bills (Warriner et al. 1984). Although bias will almost certainly exist in selfreported data, the data collected for this analysis are still important in providing more detailed insights on how and why energy-related practices are performed at home. Another limitation of the data collection is that only one member in each household was interviewed, although the interviewees were asked to describe daily routines and activities for all the members of their household. Still, members of a household could have diverse views of what home means to them and perform energy-related practices differently. Therefore, the interviewees in this paper represent their own views of prioritised meanings of the home and practices, rather than for all members of their household. However, as the purpose of this study is to understand variations in energy-consuming practices associated with meanings of the home, the notions elicited from the interviewees are argued to be sufficient insofar as the analysis within the conceptual framework is concerned. 
Table 1 Summary of monthly income and energy bill for all participating households

\begin{tabular}{|c|c|c|c|c|c|c|c|c|}
\hline Name & $\begin{array}{l}\text { Disposable } \\
\text { income }\end{array}$ & $\begin{array}{l}\text { Energy } \\
\text { bill }\end{array}$ & $\begin{array}{l}\text { Household } \\
\text { composition }\end{array}$ & $\begin{array}{l}\text { Number of } \\
\text { people }\end{array}$ & $\begin{array}{l}\text { LIHC } \\
\text { factors }\end{array}$ & $\begin{array}{l}\text { LIHC equivalised } \\
\text { energy bill }\end{array}$ & $\begin{array}{l}\text { OECD } \\
\text { factors }\end{array}$ & $\begin{array}{l}\text { OECD equivalised } \\
\text { disposable income }\end{array}$ \\
\hline Adam & $£ 2273$ & $£ 110$ & 1 & 1 & 0.82 & $£ 134$ & 1 & $£ 2273$ \\
\hline Bob & $£ 3300$ & $£ 100$ & 2 & 2 & 1 & $£ 100$ & 1.5 & $£ 2200$ \\
\hline Camilla & $£ 3020$ & $£ 116$ & 2 & 2 & 1 & $£ 116$ & 1.5 & $£ 2013$ \\
\hline Diana & $£ 880$ & $£ 80$ & 1 & 1 & 0.82 & $£ 98$ & 1 & $£ 880$ \\
\hline Eric & $£ 0$ & $£ 135$ & 2 & 2 & 1 & $£ 135$ & 1.5 & $£ 0$ \\
\hline Fiona & $£ 3200$ & $£ 128$ & $2+2$ children & 4 & 1.21 & $£ 106$ & 2.1 & $£ 1524$ \\
\hline Georgia & $£ 2000$ & $£ 148$ & 2 & 2 & 1 & $£ 148$ & 1.5 & $£ 1333$ \\
\hline Hebe & $£ 1940$ & $£ 147$ & 2 & 2 & 1 & $£ 147$ & 1.5 & $£ 1293$ \\
\hline Ivy & $£ 3400$ & $£ 140$ & $2+4$ children & 6 & 1.32 & $£ 106$ & 2.7 & $£ 1259$ \\
\hline Jane & $£ 3200$ & $£ 55$ & 2 & 2 & 1 & $£ 55$ & 1.5 & $£ 2133$ \\
\hline Kim & $£ 1800$ & $£ 50$ & 1 & 1 & 0.82 & $£ 61$ & 1 & $£ 1800$ \\
\hline Linda & $£ 1800$ & $£ 50$ & 1 & 1 & 0.82 & $£ 61$ & 1 & $£ 1800$ \\
\hline Mark & $£ 1900$ & $£ 75$ & $2+2$ children & 4 & 1.21 & $£ 62$ & 2.1 & $£ 905$ \\
\hline Nichole & $£ 1600$ & $£ 69$ & $2+1$ child & 3 & 1.07 & $£ 64$ & 1.8 & $£ 889$ \\
\hline Oliver & $£ 2000$ & $£ 62$ & 2 & 2 & 1 & $£ 62$ & 1.5 & $£ 1333$ \\
\hline Philippa & $£ 1959$ & $£ 55$ & 2 & 2 & 1 & $£ 55$ & 1.5 & $£ 1306$ \\
\hline Quinn & $£ 1200$ & $£ 31$ & 1 & 1 & 0.82 & $£ 38$ & 1 & $£ 1200$ \\
\hline Ray & $£ 2310$ & $£ 50$ & 3 & 3 & 1.07 & $£ 47$ & 2 & $£ 1155$ \\
\hline Sam & $£ 3500$ & $£ 75$ & 2 & 2 & 1 & $£ 75$ & 1.5 & $£ 2333$ \\
\hline Tara & $£ 2900$ & $£ 70$ & 2 & 2 & 1 & $£ 70$ & 1.5 & $£ 1933$ \\
\hline Barbara & $£ 1200$ & $£ 69$ & 2 & 2 & 1 & $£ 69$ & 1.5 & $£ 800$ \\
\hline Vanessa & $£ 1250$ & $£ 100$ & 4 & 4 & 1.21 & $£ 83$ & 2.5 & $£ 500$ \\
\hline Wendy & $£ 1100$ & $£ 119$ & $2+3$ children & 5 & 1.32 & $£ 90$ & 2.4 & $£ 458$ \\
\hline Yvonne & $£ 800$ & $£ 96$ & $3+2$ children & 5 & 1.32 & $£ 73$ & 2.6 & $£ 308$ \\
\hline Anna & $£ 2500$ & $£ 96$ & $2+1$ child & 3 & 1.07 & $£ 90$ & 1.8 & $£ 1389$ \\
\hline Mean & $£ 2041$ & $£ 89$ & & & & $£ 86$ & & $£ 1320$ \\
\hline
\end{tabular}

\section{Analysis and findings}

Four types of prioritised meanings of home emerged from the empirical data: (i) home as a continuous project; (ii) home as a safe and comfort haven; (iii) home for family activities along the life course; and (iv) home for

Table 2 Modified OECD equivalisation factors for household income (OECD 2013)

\begin{tabular}{ll}
\hline & Equivalisation factor \\
\hline First adult & 1 \\
Second and subsequent adults & 0.5 \\
Children aged 14-18 & 0.5 \\
Children under 14 & 0.3 \\
\hline
\end{tabular}

hospitality or house exchange. Table 4 summarises the prioritised meanings of home associated with the respondent for all participating households. It shows that there is no clear link between the level of household equivalised energy bill and their prioritised meaning of

Table 3 Equivalisation factors for fuel bills under the LIHC definition of fuel poverty (DECC 2014)

\begin{tabular}{ll}
\hline Number of people in the household & Equivalisation factor \\
\hline One & 0.82 \\
Two & 1.00 \\
Three & 1.07 \\
Four & 1.21 \\
Five or more & 1.32 \\
\hline
\end{tabular}




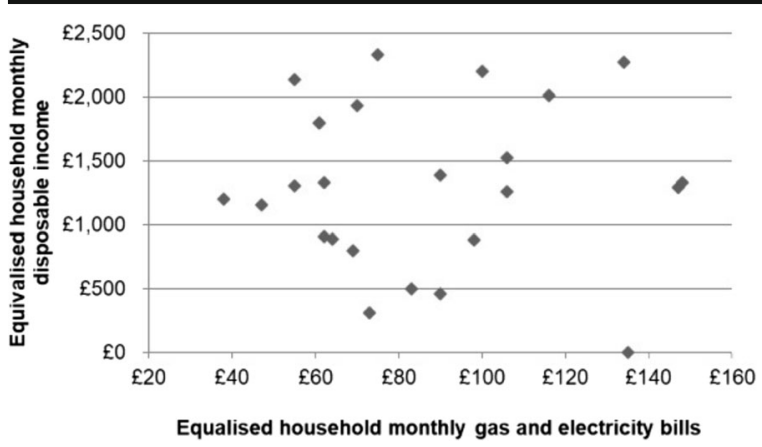

Fig. 2 Equivalised household energy bill and income among the interviewees ${ }^{\mathrm{a}}$. ${ }^{\mathrm{a}}$ Only 24 dots can be seen instead of 25 dots, because two of the households have the same equivalised household monthly disposable income (£1800) and the same equivalised household monthly gas and electricity bills (£61) the home, except that both participating households that prioritise their home for hospitality share higher energy bills than the mean $£ 84$ (Table 4).

The identified meanings of the home from this study could also be found in previous studies like Aune (2007) and Gram-Hanssen and Darby (2018). Their aspects have all been captured in the categories of meanings of the home in this paper, but the categorisation here is done differently to better capture broader energy-related practices. The research objective here is to explore the interconnection between meanings of home and energyrelated practices, whilst in Gram-Hanssen and Darby (2018), the focus was on the role of smart technologies in relation to different concepts of home. Compared to those categories, for this paper, security is related to the category of home as a safe and comfort haven; the

Table 4 Summary of prioritised meaning of the home associated with the respondent for all participating households ${ }^{\mathrm{a}}$

\begin{tabular}{|c|c|c|c|c|}
\hline Name & $\begin{array}{l}\text { OECD equivalised } \\
\text { disposable income }\end{array}$ & $\begin{array}{l}\text { LIHC equivalised } \\
\text { energy bill }\end{array}$ & Household composition & Prioritised meaning of the home \\
\hline Bob & $£ 2200$ & $£ 100$ & 2 & A continuous project \\
\hline Sam & $£ 2333$ & $£ 75$ & 2 & A continuous project \\
\hline Oliver & $£ 1333$ & $£ 62$ & 2 & A continuous project \\
\hline Hebe & $£ 1293$ & $£ 147$ & 2 & A safe and comfort haven \\
\hline Eric & $£ 0$ & $£ 135$ & 2 & A safe and comfort haven \\
\hline Adam & $£ 2273$ & $£ 134$ & 1 & A safe and comfort haven \\
\hline Camilla & $£ 2013$ & $£ 116$ & 2 & A safe and comfort haven \\
\hline Tara & $£ 1933$ & $£ 70$ & 2 & A safe and comfort haven \\
\hline Barbara & $£ 800$ & $£ 69$ & 2 & A safe and comfort haven \\
\hline Kim & $£ 1800$ & $£ 61$ & 1 & A safe and comfort haven \\
\hline Linda & $£ 1800$ & $£ 61$ & 1 & A safe and comfort haven \\
\hline Jane & $£ 2133$ & $£ 55$ & 2 & A safe and comfort haven \\
\hline Philippa & $£ 1306$ & $£ 55$ & 2 & A safe and comfort haven \\
\hline Ray & $£ 1155$ & $£ 47$ & 3 & A safe and comfort haven \\
\hline Quinn & $£ 1200$ & $£ 38$ & 1 & A safe and comfort haven \\
\hline Fiona & $£ 1524$ & $£ 106$ & $2+2$ children & For family activities along life course \\
\hline Ivy & $£ 1259$ & $£ 106$ & $2+4$ children & For family activities along life course \\
\hline Wendy & $£ 458$ & $£ 90$ & $2+3$ children & For family activities along life course \\
\hline Anna & $£ 1389$ & $£ 90$ & $2+1$ child & For family activities along life course \\
\hline Vanessa & $£ 500$ & $£ 83$ & 4 & For family activities along life course \\
\hline Yvonne & $£ 308$ & $£ 73$ & $3+2$ children & For family activities along life course \\
\hline Nichole & $£ 889$ & $£ 64$ & $2+1$ child & For family activities along life course \\
\hline Mark & $£ 905$ & $£ 62$ & $2+2$ children & For family activities along life course \\
\hline Georgia & $£ 1333$ & $£ 148$ & 2 & For hospitality or house exchange \\
\hline Diana & $£ 880$ & $£ 98$ & 1 & For hospitality or house exchange \\
\hline Mean & $£ 1320$ & $£ 86$ & & \\
\hline
\end{tabular}

$\overline{{ }^{a} \text { Within each prioritised meaning of the home, the respondents are ranked from the highest to the lowest equivalised energy bill in the table }}$ 
aspect of activity relates here to the concept of home as a place for family activities and home as a continuous project; relationships relate here to the concept of home as a space for hospitality and a place for family activities, whilst the aspect of values are covered across all four categories. Key findings are presented and discussed below to indicate whether and how the interviewees' prioritised meanings of the home affected the elements of energy-consuming practices, which could lead to increased levels of energy use at home.

\section{Home as a continuous project}

For some interviewees, home is a continuous project to work on. One interviewee, Bob, explained:

On the house, there is always something to do. You never stop. [...] The time you replaced something, it's time to decorate again, because you want to change. There is always something to do, always.

In this sample, households who view their home as a continuous project are all homeowners. In contrast, those renting in the UK have no right to insulate or refurbish their homes. Aune (2007) and Pettifor et al. (2015) have identified that renovating the home can be an opportunity for adding insulation. Likewise, the research presented here also shows that old appliances, especially in the kitchen, are more likely to be replaced if the house is being refurbished, as it is perceived as more convenient to schedule replacements than at other times.

We decided we need to renew the kitchen... Everything would have to be replaced... I think we would replace them [the appliances].

[When refurbishing the kitchen,] we changed the appliances, but it was the same appliances in there, we just changed and upgraded the units. We replaced all the furniture, and we put new dishwasher, new cooker, and new fridge. So we replaced the kitchen. But they were all there, similar appliances were there. So there was already a dishwasher, there was already a fridge built in, there was already a cooker, and an extract fan. We just replaced them all.

Like Pettifor et al. (2015), the analysis here indicates that the interviewees were more likely to replace their old inefficient appliances and insulate their home during periods of refurbishment, and this was particularly the case for those who view their home as a continuous project and possibly refurbish their home more often than others. Among the 25 households interviewed, 15 were owners and five had refurbished their kitchen in the past. These five households all replaced their appliances during the refurbishment not because they were broken but because they wanted new appliances that fit the kitchen redesign, or they no longer liked their old appliances. On the other hand, some interviewees bought new appliances whilst continuing to use the old ones such as fridges and freezers, which can lead to increased energy use.

We've got electricity in the sheds, so we also got a fridge freezer and a dryer in the shed... There is another fridge in the kitchen.

This indicates that for interviewees who felt their home was a continuous project, the material elements of practice were influential, which then affects energy consumption. Therefore, the prioritised meaning of home as a continuous project could lead to more frequent change of energy-using appliances. There have been regulations requiring labelling energy efficiency on all energy-related products to be sold on the market (the 'Policies for reducing household energy consumption in the UK' section); however, there have not been any policies aimed at preventing people from using inefficient appliances.

The findings also show that the high cost of insulation work could sometimes discourage the interviewees from insulating their homes. One way to circumvent this issue was that many carried out the double-glazing of their windows incrementally, avoiding a large initial financial outlay. Other interviewees did not install double-glazing as they felt they would not recoup the cost through lower energy bills. For example, although for Bob the home was a continuous project, he did not insulate his windows or roof due to the expense.

Possibly, [I will insulate] the roof. But if I got a lot of money, yes; if not, that could stay.

Similarly, whilst Oliver and his wife decided to replace the kitchen, cost concerns prevented external wall insulation. These examples indicate that the meaning of the home as a continuous project could affect the materials of practices, whilst refurbishments could also be 
constrained by high cost and the interviewees' levels of motivation for reducing their energy costs. Reduced cost or available grants, such as the now defunct Green Deal Home Improvement Fund and the Warm Front Scheme (DECC 2013a, 2015b), have been incentives for some interviewees to improve insulation. However, not all qualified for the grants as they depended on age, income, employment, tenure type and the age and type of the property.

Home as a safe and comfort haven

Some interviewees showed interest in saving energy at home but still used more energy than average participants, due to other priorities such as the safety and security of their home, or their comfort and convenience. This prioritised meaning of home as a safe and comfort haven shaped the materials and procedures of their practices, affecting their energy consumption.

For those who prioritise safety at home, left-on lights are typical for avoiding burglars when being away after dark.

When you go out especially at night, you leave the light on; so, you know, it's less targeted by burglars.

If these interviewees had automatic switches for the lights to switch on at night, they may be less likely to leave the lights on during daytime when the perceived safety risk was low. This is not suggesting that purchasing and using an automatic switch will definitely reduce embedded $\mathrm{CO}_{2}$ emissions compared to leaving the lights on during daytime, as this would depend on various factors, including the $\mathrm{CO}_{2}$ emissions embedded in the manufacture, transportation, retail and disposal of the automatic switch; the energy intensity of the left on light; the $\mathrm{CO}_{2}$ emissions intensity of the electricity used for lighting; and whether there are rebound effects due to cost savings from turning off the left-on light (Druckman and Jackson 2009; Skudder et al. 2016). Rather, the example shows the possibility of changing the materials of practices whilst still meeting the householders' prioritised meaning of home. The analysis presented here argues that it is important to consider all these factors when evaluating whether a policy measure, or any change in the materials, procedures and meanings of energy-related practices, will lead to a reduction of total $\mathrm{CO}_{2}$ emissions in the economy.
For those who prioritise comfort and privacy at home, their focus is on how they heat, light and clean their homes to meet these goals. For example, some interviewees avoided insulation work because of its interruption to everyday life. In this case, the prioritised meaning of home as a comfort haven has stopped these householders from changing materials in relation to energy use.

You know when you get old; you don't want a big mess in the house. It's difficult.

A 'warm home' was a goal commonly expressed by the interviewees. To this end, some interviewees leave the heating on when away or set it to come on before they arrive home, even though some of them reported aspirations to reduce their energy bills. Among those who prioritised thermal comfort, their reasoning was the time it took to warm their homes. In this case, the smart home technologies could potentially allow people to enjoy the comfort and convenience they pursue but with less energy input, indicating how the change of materials could meet people's prioritised meaning of home whilst potentially reduce energy use.

What I do sometimes is like heat the bathroom overnight, so that it doesn't get chilly when I use it the next morning.

Besides thermal comfort, the data show that other ways for feeling comfortable at home include creating a homely atmosphere through personalised design and spaciousness. For example, Georgia talks about leaving lights on in every room during the evening, even when not at home, to make the atmosphere nicer or more welcoming for when they come back.

I like to use side lights. I have lots of table lights. And I have economy bulbs in all my lights now. So when I come in my house, when it gets dark in the evening in the winter, I light in the hall. The lights in the lounge, the lights in the kitchen, the lights in the bedroom and the landing and the study are on all the time. I just like to have the house lit.

In Georgia's example, she changed the materials (i.e. energy-efficient bulbs) in order to reduce her electricity consumption. However, she would not turn off the lights in unoccupied rooms, as this sacrifices her perceived 
view of the space. This is consistent with findings from Wilhite and Ling (1992), who have noted that some people perceive a dark house as a 'sad' house. This finding is also in line with Shove (2017), who argued that although the energy efficiency programmes have an impact, they cannot stop the changing complexities of practices and the increasingly energy-intensive lifestyles people are encouraged to lead. Furthermore, another sphere of influence to point out is the media, which has a role in promoting lighting rooms with multiple appliances to create a cosy, spacious, welcoming and homely atmosphere. Whilst this did not emerge in the conversations with the interviewees, according to Crosbie and Guy (2008), media played an important role in shaping householders' lighting, suggesting that whilst stringent regulations on energy-efficient lighting are needed, support from the design, production and marketing industries of household lighting is also necessary in promoting environmentally friendly lighting schemes using fewer lights.

The interviewees, including those from low-income households, intending to save on their energy were only successful to a certain level. Respondents clearly placed importance on some theoretically 'avoidable' consumption such as overheating. They explained that once they have reduced the energy bills to an 'affordable level', they had little interest in going further. If the energy price is low enough to leave some appliances on, then the interviewees are more likely to do so, especially if it increases their levels of safety, convenience or comfort. For example, Philippa is always conscious about reducing her energy bills, but she is not bothered about turning off the Wi-Fi router whilst it is not being used. She knows that doing so does not save much electricity.

I worked out how much it costs, and it's tiny, really tiny. As I said, last year, I did go around and rate for my appliances of how much [energy] they used; and the router was so small. It wasn't even worth turning it on and off.

Consistent with Aune (2007) who suggested that policy instruments should support rather than threaten the meaning of home as a haven, the empirical findings here indicate that householders are more likely to engage in policies targeted at reducing energy bills if their non-financial goals, such as safety, comfort and convenience, are not compromised. This is also consistent with findings from Haines and Mitchell (2014), who found that householders are only likely to install energysaving technologies if the installation fits in with the household's existing lifestyle, or if it improves the comfort and aesthetics they pursue at home, without reducing space or causing disruption to daily life.

Home for family activities along life course

Household energy consumption is influenced by the amount of time people spend at home, as well as the energy used for conducting their activities (GramHanssen and Petersen 2004). In general, among retired interviewees or those working at home full or part-time, more energy was used for space heating, cooking, lighting, cleaning and computer use during weekdays, as influenced by their schedules. People's life courses can also influence their time and activities at home, explained by Giele and Elder (1998), as a sequence of events and roles that the householders enact over time (e.g. grown-up children moving out or couples having their first baby). The interviewee Nicole felt that what home means to her changed completely before and after she went on maternity leave, especially during weekdays. Prior to her leave, the house was mainly for eating and sleeping, whilst during her leave, the house became more of a living space. Therefore, the level of engagement with materials in relation to energy use changed significantly throughout her life courses.

Before [our baby was born], I think a lot less housework done when I was working [outside], and the house was a lot less organised, a lot less intensively used. It kind of feels like when I am working, the house is there for eating and sleeping; whereas when I am off on leave, the house is for living, and we spend most of the day there, and it's used a lot more. TV is used more, radio is used more, the phone is used more, the lamp is used more, [and] the heating is used more, because the two of us are in there. And there is a lot more money spent [on energy] when I am at home.

This case demonstrates the dynamic nature of meanings of home over the life course. Performances of cooking, heating, entertaining and other energyconsuming practices may also vary over the life course along with changed schedules, and therefore so too may 
the appropriate design of policy instruments needed to achieve energy reduction targets.

Home for hospitality or house exchange

Many interviewees host guests frequently at home for socialising, and consequently use much more gas or electricity for space heating, cooking, cleaning and catering, to ensure their guests' comfort. Frequently having overnight guests could lead to overall higher energy consumption levels at home. For example, Diana has guests staying overnight almost every weekend, during which she cooks more often and keeps the house warmer for her guests.

Most of the time, weekend I have guests; so it's more heating, because you don't want your guests to be cold, you know. [...] So I just always make sure the heating is on.

Georgia participates in house exchanges with families from Australia for about 3 months every year. As was clear in her quarterly energy bills, much more energy was used when her Australian exchange visitors stayed over. This might be attributed to their visitors not being accustomed to the colder UK weather, or their lack of consideration of consumption as they were not paying for utilities. Furthermore, in response to feedback from visitors, the house exchanges prompted Georgia to buy a tumble dryer and a secondary heater in response to their visitors' feedback. Since then, they have used both appliances for themselves frequently during winter.

After the house exchange. [...] we realised when people come to our house, they couldn't bear not having a tumble dryer. So [for] our foreign visitors, $[\ldots]$ we bought a tumble dryer. We've never had one before.

In Georgia's case, the prioritised meaning of home for hospitality has changed not only the materials they have (i.e. tumble dryer and secondary heater) but also their own performances of laundry and heating practices. This finding is different from previous research by Agbemabiese et al. (1996), who have identified that some people use more energy for space heating/ cooling at home to make sure their guests are comfortable, but did not change the hosts' own performances of energy-consuming practices after guests left.

The age of the guests also affects the amount of extra energy used. The interviewees reported that older guests sometimes need more space heating or lighting due to their health conditions, such as the case of Ivy, whose parentsin-law come to dinner once a week, leading to her increasing the temperature setting, as they are more sensitive to the cold.

I might turn the temperature up a little bit when we have guests over, because grandparents tend to find it colder. They like it a bit warmer than we do.

The results indicate that the prioritised meaning of the home as a space for hospitality could change the materials and procedures of energy-consuming practices, which in turn influence total energy consumption. Moreover, the changes in these elements also relate to the diverse comfort levels required by visitors, especially those from different age groups. This is significant nowadays given the continuing popularity of hosting enabled by online platforms such as Airbnb (www.airbnb.com). The growth of this particular hospitality practice, which sees homes and domestic spaces shared more efficiently, suggests a trajectory towards more sustainable ways of being (Luchs et al. 2011). However, for hosts competing in this market and the sometimes-hostile online rating system (Touval 2017), thermal comfort and other everyday conveniences can become a priority for hosts hoping to ensure positive guest feedback and increase the desirability of their house. Whilst the case above suggests a desire to match expectations of comfort for house exchange and general hospitality rather than hosting, it is likely that such patterns of homemaking are increasing with significant impacts on household energy consumption through changed materials and procedures of practices.

In summary, prioritised meanings of the home to interviewees, whether it is a continuous project, a safe and comfort haven, a space for family activities, or for hospitality and house exchange, can affect the materials and procedures of energy-consuming practices at home (Table 5), which then influence people's energy consumption levels. Moreover, the findings indicate that the scale of influence relates to household composition, tenure type and the age of household visitors.

\section{Discussion}

From the findings presented above, it is clear that the interviewees perceive their home differently in terms of its prioritised meaning. As illustrated in Fig. 3, 
Table 5 Influence on the elements of energy-consuming practices from prioritised meanings of the home

\begin{tabular}{|c|c|c|c|}
\hline $\begin{array}{l}\text { Prioritised meaning of the } \\
\text { home }\end{array}$ & $\begin{array}{l}\text { Materials of energy-consuming } \\
\text { practices }\end{array}$ & $\begin{array}{l}\text { Procedures of energy-consuming } \\
\text { practices }\end{array}$ & $\begin{array}{l}\text { Meanings of energy-consuming } \\
\text { practices }\end{array}$ \\
\hline $\begin{array}{l}\text { Home as a continuous } \\
\text { project }\end{array}$ & $\begin{array}{l}\text { Home insulation; } \\
\text { Refurbishment and change } \\
\text { of appliances }\end{array}$ & & \multirow{4}{*}{$\begin{array}{l}\text { Not shown from empirical } \\
\text { data as being influenced by } \\
\text { the prioritised meaning of the } \\
\text { home }\end{array}$} \\
\hline $\begin{array}{l}\text { Home as a safe } \\
\text { and comfort haven }\end{array}$ & $\begin{array}{l}\text { Unchanged insulation; } \\
\text { Opportunities for automatic } \\
\text { switches and smart home } \\
\text { technologies }\end{array}$ & Left on lights and space heating & \\
\hline $\begin{array}{l}\text { Home for family } \\
\text { activities along } \\
\text { Life course }\end{array}$ & & $\begin{array}{l}\text { The level of engagement with } \\
\text { appliances throughout life courses; } \\
\text { Changed schedules }\end{array}$ & \\
\hline $\begin{array}{l}\text { Home for hospitality or } \\
\text { house exchange }\end{array}$ & $\begin{array}{l}\text { Change materials } \\
\text { for guests }\end{array}$ & $\begin{array}{l}\text { Change of procedures during guests' } \\
\text { stay; } \\
\text { Adopt and use added materials for } \\
\text { hospitality in daily routines after } \\
\text { guests leave }\end{array}$ & \\
\hline
\end{tabular}

prioritising different meanings of the home influences the interviewees' practices in everyday life through their associated materials and procedures, which could lead to particularly high levels of energy consumption. Understanding the influence of prioritised meanings of the home and how this differs across households can provide valuable insights for policymakers and the design of smart home technologies to affect the materials and procedures of practices in order to reduce the energy involved.

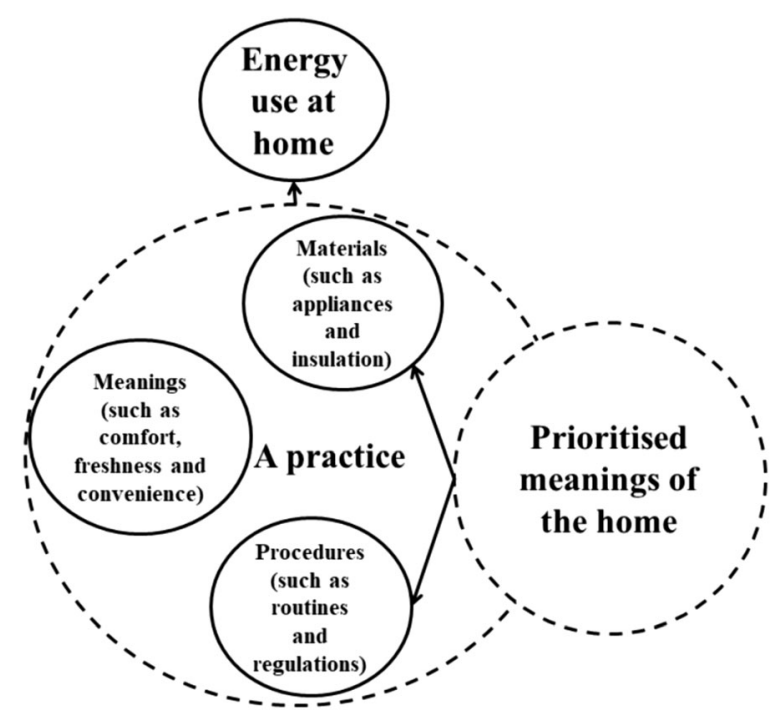

Fig. 3 Understanding energy use through practices and prioritised meanings of the home
An angle of the design and marketing of smart technologies for reducing energy consumption could target how the prioritised meanings of the home can be supported with less energy input or associated $\mathrm{CO}_{2}$ emissions. Consistent with Aune (2007) and Pettifor et al. (2015), this paper shows that materials have been changed more frequently among householders who perceive the home as a continuous project, since it is more convenient to replace inefficient appliances and improve insulation during refurbishment or redecoration. The more frequent change of materials can increase or reduce energy consumption, depending on whether the householders continue to use their old appliances, and considering any rebound effects. As argued by Vlasova and Gram-Hanssen (2014), whether the retrofit projects would save energy is conditional upon how they are compatible with the household's everyday practices. There are opportunities for energy-related assessments to a kitchen or bathroom redesign, to enhance energy efficiency improvement during renovations. In line with Crosbie and Guy (2008), support from the design, manufacture and marketing industries is necessary to inform households who are planning to refurbish their home about the potential of improving their properties' energy efficiency. Energy companies could consider collaborating with these industries to promote insulation and energy-efficient design, which would assist the energy companies in achieving their ECO target. However, as mentioned previously, improving energy efficiency at home does not necessarily lead to energy saving due to 
rebound effects; therefore, other interventions for reducing household energy use are also needed.

Materials can also change among the interviewees who prioritise home as a place for hospitality. As shown in the 'Home for hospitality or house exchange' section, they can change the materials initially purchased for their visitors to use, and then incorporate these into altered performances of their practices after their visitors leave. Most of these households would consume more energy for space heating, cooking and cleaning to make sure that their visitors are comfortable. They may increase their energy use even more if their visitors include older people and younger children. For these households, smart home technologies that comprise networks of sensors, monitors, interfaces, appliances and devices (Wilson et al. 2017) could potentially help reduce the total energy used in the hosts' home and the visitors' home through automatically turning off left-on appliances or altering heating systems in unoccupied homes or rooms. Therefore, in order to provide convenience to householders according to their practices, designers of smart metres could consider including a sensor and automatic control that will detect if no one is at home or if the windows are open, modify temperatures and turn lights on or off to maintain safety at home at a reduced level of energy use. Electricians then need to be trained to understand these options and how to install them. The marketing of the functionalities of smart home technologies could emphasise the convenience and energy-saving potential especially for householders who are often away from home in evenings and weekends. The increasing popularity of hosting can provide an opportunity to propagate options for energy efficiency that increase comfort and thermal performance.

Of those interviewed for this study, few used an energy management system to find out how much electricity was consumed by individual appliances and to track their total monthly electricity consumption through regular metre readings. The electricity consumed at peak time compared to off-peak time is likely to be more emission-intensive, as a lower percentage of total electricity supply would be generated from renewables (Stoll et al. 2014). Overall, the findings show that more detailed information provided by an energy management system encouraged some of them to change to less emission-intensive performances of practices through reducing peak-time energy use, but did not lead to changes in all practices or among all those with an energy management system, as this can also be affected by their routines, and their prioritised meanings of the home.

New technologies, such as the Nest or Hive smart thermostat that allows householders to control heating at home remotely, can benefit households that pursue comfort through indoor temperature, convenience through automatic setting, and potential energy savings from information on consumption and daily routines, leading to potentially reducing energy usage especially at peak times. However, whether smart home technologies could lead to reduced energy use is not clear. As argued by Strengers (2008) and GramHanssen (2011), household practices and expectations of comfort could change along with the introduction of new technology, notwithstanding the potential for individual interpretation and domestication. Smart home technologies could intensify existing energy-intensive services (e.g. audio-visual entertainment) and add new energy services (e.g. pre-heating homes) due to an increased level of convenience in managing energy use at home (Wilson et al. 2017). Therefore, availability of smart technology functionality is, on its own, not guaranteed to result in reduced consumption-whether it is due to reluctance to have sensors installed in homes, the information-behaviour gap or even, increased levels of demand as new technologies make new levels and standards of 'comfort' achievable (Gram-Hanssen 2011; Wilson et al. 2017). However, automatic functions may offer the potential to reduce consumption without a change in routine. Thinking through the meanings of home, and how the elements of practices (especially new technology) could change energy-consuming practices, would potentially allow for the consideration of the energy consumption impact of smart home technology design and open up opportunities to achieve reductions in overall residential energy use. How the implications on the design and marketing of smart home technologies could link with the available policy tools is summarised in Table 6, based on the previous and existing policies introduced in the 'Policies for reducing household energy consumption in the UK' section.

\section{Conclusions}

In this study, the findings show that the materials and procedures of practices at home can be influenced by the prioritised meanings of the home, which provide 
Table 6 Policy to link with smart home technologies considering the connection between prioritised meanings of the home and practices

Policies and regulations

Energy Information Regulations

Building Regulations

Energy Company Obligation (ECO)

Landlord's Energy Saving Allowance

(LESA) (04/2004-04/2015);

Green Deal Home Improvement

Fund (06/2014-09/2015)

Energy Saving Campaigns

Smart metre rollout scheme
Suggestions

Link with energy assessments on kitchen or bathroom redesign and provide options of smart home technologies, especially among householders who prioritise their home as a continuous project.

Need support from the design, manufacture and marketing industries to inform households the potential of improving their properties' energy efficiency.

Energy companies could collaborate with the design, manufacture and marketing industries on promoting insulation and energy-efficient design, help reach their ECO targets.

For comfort of rented properties, policymakers could increase the required EPC rating to D or $\mathrm{C}$ of rented properties; and work with rental agencies to advertise the LESA allowance and the benefits of installing smart home technologies.

Policymakers should continue work with local councils and energy suppliers, supporting energy efficiency improvements and smart home technologies financially with government spending generated from income taxation instead of loans.

Consider how to support the meanings of home with less energy input, for example, with better design and marketing of smart home technologies, instead of focusing on information provision based on cost or environmental issues alone.

Designers of smart metres could consider including a sensor and automatic control together with a metre. Provide trainings required.

Market the smart metres emphasising the convenience and potential energy saving especially for householders who are often away from home in evenings and weekends. significant implications for future policy and technology design in relation to energy use at home. For the interviewees who prioritise home as a continuous project, appliance replacement and improved insulation are more likely during refurbishment and redecoration. As such, there are opportunities for energy assessments of kitchen or bathroom redesigns to enhance energy efficiency. If people prioritise home as a space for comfort, convenience and security, they may be more likely to adopt smart home technologies to reduce their energy use whilst improving the levels of convenience, comfort and security at home. If the home is prioritised as a space for work and activities during weekdays, people could be more flexible to shift the performance of energyconsuming practices from peak time to off-peak, which would cut related $\mathrm{CO}_{2}$ emissions. Household energy demand reduction schemes could also link with a work-from-home scheme and explore whether employers should provide their employees with financial compensation to support energy efficiency, considering both fuel consumption saved from avoiding commuting and the extra energy used at home for working. For those who prioritise home as a place for hospitality, their energy consumption may increase as a result. On the other hand, the hospitality may contribute to energy reduction in the visitors' home through ensuring the turning-off of lights and appliances when unoccupied. Like Aune (2007) and Gram-Hanssen and Darby (2018), the four types of meanings of home are not exclusive. Householders can perceive their home in more ways than one, although they are likely to prioritise one meaning over others. Understanding how different prioritised meanings of home can shape and influence people's everyday performances of practices provides insight for future policy and smart home technology design, through focusing on how elements of practices can be altered. Meanwhile, these have to be able to be assimilated into prioritised meanings of home if they are to be easily and rapidly adopted.

In conclusion, household energy consumption relates to the prioritised meanings of the home to householders, which influence the materials and procedures of their energy-consuming practices. Although the empirical case study presented here is undertaken in the UK, the integrated approach could be applied more broadly. The results show that there is potential for policymakers and smart technology industries to consider not only altering the materials and procedures of practices but also supporting or challenging various meanings of the home, and exploring whether the prioritised meanings 
can be supported within the significant energy demand reductions implied by commitments such as the Paris Agreement and the Net Zero emissions target in the UK. The findings also indicate the potential for a differentiated and targeted approach, which speaks to and supports the role that the home plays in people's lives and well-being.

Acknowledgements Many thanks to four anonymised experts who commented on earlier versions of this paper. Particular thanks go to the Tyndall Manchester team, who have been very supportive to this work and offered valuable suggestions for improvement. Extraordinarily gratefulness goes to all participants in the empirical work. This work would not have been possible without them.

Funding This work was funded by the School (now Department) of Mechanical, Aerospace and Civil Engineering and the Sustainable Consumption Institute at the University of Manchester.

\section{Compliance with ethical standards}

Conflict of interest The authors declare that they have no conflict of interest.

Open Access This article is licensed under a Creative Commons Attribution 4.0 International License, which permits use, sharing, adaptation, distribution and reproduction in any medium or format, as long as you give appropriate credit to the original author(s) and the source, provide a link to the Creative Commons licence, and indicate if changes were made. The images or other third party material in this article are included in the article's Creative Commons licence, unless indicated otherwise in a credit line to the material. If material is not included in the article's Creative Commons licence and your intended use is not permitted by statutory regulation or exceeds the permitted use, you will need to obtain permission directly from the copyright holder. To view a copy of this licence, visit http://creativecommons.org/licenses/by/4.0/.

\section{References}

Agbemabiese, L., Berko, Jr K. and du Pont, P. (1996). Air conditioning in the tropics: cool comfort or cultural conditioning? Paper presented at the 1996 ACEEE Summer Study on Energy Efficiency in Buildings: Human Dimensions of Energy Consumption, Washington, D.C.

Anderson, K. (2015). Duality in climate science. Nature Geoscience, 8, 898-900.

Anderson, K., \& Bows, A. (2011). Beyond dangerous climate change: emission pathways for a new world. Philosophical Transactions of the Royal Society A, 369, 20-44.
Attride-Stirling, J. (2001). Thematic networks: an analytic tool for qualitative research. Qualitative Research, 1, 385-405.

Aune, M. (2002). Users versus utilities - the domestication of an energy controlling technology. In A. Jamison \& H. Rohracher (Eds.), Technology Studies \& Sustainable Development. Profil Verlag: Munich.

Aune, M. (2007). Energy comes home. Energy Policy, 35, 54575465.

Aune, M., Godbolt, Å. L., Sørensen, K. H., Ryghaug, M., Karlstrøm, H., \& Næss, R. (2016). Concerned consumption. Global warming changing household domestication of energy. Energy Policy, 98, 290-297.

Bachelor, L. (2013). Green deal debt may have to be repaid before property sold. The Guardian. [online] Available at: http://www.theguardian.com/money/2013/may/19/greendeal-debt-repaid [accessed 04/02/2019].

Balcombe, P., Rigby, D., \& Azapagic, A. (2014). Investigating the importance of motivations and barriers related to microgeneration uptake in the UK. Applied Energy, 130, 403-418.

BEIS. (2017). Energy consumption in the UK data tables. London: Department for Business, Energy and Industrial Strategy.

BEIS. (2018a). Final UK greenhouse gas emissions national statistics 1990-2016. London: Department for Business, Energy and Industrial Strategy.

BEIS. (2018b). Energy Company Obligation ECO3: 2018 - 2022. Final Stage Impact Assessment. London: Department for Business, Energy and Industrial Strategy.

Blunt, A., \& Dowling, R. (2006). Home. London and New York: Routledge.

Boardman, B. (2007). Home truths: a low-carbon strategy to reduce UK housing emissions by $80 \%$ by 2050. ECI Research Report 34. Environmental Change Unit, University of Oxford.

Capstick, S., Lorenzoni, I., Corner, A., \& Whitmarsh, L. (2014). Prospects for radical emissions reduction through behaviour and lifestyle change. Carbon Management, 5, 429-445.

Chitnis, M., Sorrell, S., Druckman, A., Firth, S. K., \& Jackson, T. (2014). Who rebounds most? Estimating direct and indirect rebound effects for different UK socioeconomic groups. Ecological Economics, 106, 12-32.

Climate Change Act (2008). London, UK: TSO. [online] Available at: http://www.legislation.gov.uk/ukpga/2008/27 /pdfs/ukpga_20080027_en.pdf [accessed 04/02/2019].

Collins, J., Thomas, G., Willis, R., and Wilsdon, J. (2003). Carrots, sticks and sermons: Influencing public behaviour for environmental goals. A Demos/Green Alliance report produced for Defra. London: HMSO, Department for Environment, Food and Rural Affairs.

Committee on Climate Change. (2008). 2008 Building a lowcarbon economy - the UK's contribution to tackling climate change. Norwich: The Stationery Office.

Committee on Climate Change. (2016). UK climate action following the Paris Agreement. London: Committee on Climate Change.

Crosbie, T., \& Guy, S. (2008). Enlightening energy use: the coevolution of household lighting practices. International Journal of Technology Management, 9, 220-235.

Darnton, A., Verplanken, B., White, P., \& Whitmarsh, L. (2011). Habits, routines and sustainable lifestyles. Summary Report. 
London: Department for Environment Food and Rural Affairs.

DCLG. (2011). The English Indices of Deprivation 2010. London: Department for Communities and Local Government.

DECC. (2010). The Green Deal: a summary of the Government's Proposals. URN: 10D/996. London: Department of Energy and Climate Change.

DECC. (2013a). Warm front scheme. House of Commons Library. Standard Note: SN/SC/06231. London: Department of Energy and Climate Change.

DECC. (2013b). UK housing energy fact file. URN: 13D/276. London: Department of Energy and Climate Change.

DECC. (2014). Annual fuel poverty statistics report, 2014. URN: 14D/146. London: Department of Energy and Climate Change.

DECC. (2015a). Domestic Green Deal and Energy Company Obligation in Great Britain. Department of Energy and Climate Change: Headline report. London.

DECC. (2015b). Domestic Green Deal and Energy Company Obligation in Great Britain. Headline report. Department of Energy and Climate Change: London.

DECC. (2015c). Smart meters, Great Britain. Quarterly report to end September 2015. URN: 15D/522. London: Department of Energy and Climate Change.

Department for Trade and Industry. (2007). Meeting the energy challenge: a White Paper on Energy. London: TSO.

Després, C. (1991). The meaning of home: literature review and directions for future research and theoretical development. Journal of Architectural and Planning Research, 8, 96-115.

Druckman, A., \& Jackson, T. (2009). The carbon footprint of UK households 1990-2004: a socio-economically disaggregated, quasi-multi-regional Input-Output model. Ecological Economics, 68, 1066-2077.

Ellsworth-Krebs, K., Reid, L., \& Hunter, C. J. (2015). Home-ing in on domestic energy research: "house," "home," and the importance of ontology. Energy Research \& Social Science, $6,100-108$.

Energy Conservation, England and Wales (2015). The energy efficiency (private rented property) (England and Wales) Regulations 2015 No. 962.

Energy Information Regulations 2011/1524. London: HMSO.

Foulds, C., \& Powell, J. (2014). Using the Homes Energy Efficiency Database as a research resource for residential insulation improvements. Energy Policy, 69, 57-72.

Giele, J. Z., \& Elder, G. H. (1998). Methods of life course research: quantitative and qualitative approaches. London: Sage.

Gram-Hanssen, K. (2011). Understanding change and continuity in residential energy consumption. Journal of Consumer Culture, 11, 61-78.

Gram-Hanssen, K. (2014). New needs for better understanding of household's energy consumption - behaviour, lifestyle or practices? Architectural Engineering \& Design Management, 10, 91-107.

Gram-Hanssen, K., \& Darby, S. S. J. (2018). "Home is where the smart is"? Evaluating smart home research and approaches against the concept of home. Energy Research and Social Science, 37, 94-101.

Gram-Hanssen, K., and Petersen, K. N. (2004). Different everyday lives - different patterns of electricity use. In Proceedings of the 2004 American Council for an Energy Efficient Economy Summer Study in Buildings, Washington, D.C.

Guy, S. (2006). Designing urban knowledge: competing perspectives on energy and buildings. Environment \& Planning $C$, 24, 645-659.

Guy, S., \& Moore, S. A. (2007). Sustainable architecture and the pluralist imagination. Journal of Architectural Education, 60, $15-23$.

Guy, S., \& Shove, E. (2000). A sociology of energy, buildings and the environment: constructing knowledge, designing practice. London: Routledge.

Haines, V., \& Mitchell, V. (2014). A persona-based approach to domestic energy retrofit. Building Research and Information, 42, 462-476.

HM Government (2019). The Climate Change Act 2008 (2050 Target Amendment) Order 2019. [online] Available from: http://www.legislation.gov.uk/uksi/2019/1056 /contents/made [accessed 27/08/2020].

HM Revenue and Customs (2016). Deductions: General rules: Main types of expenses: Landlord's Energy Savings Allowance (LESA). [online] Available at: https://www.gov. uk/hmrc-internal-manuals/property-incomemanual/pim2072 [accessed 28/04/2017]

IPCC (Intergovernmental Panel on Climate Change). (1990). Climate change the IPCC Scientific Assessment. Cambridge: Cambridge University Press.

Lees, E. W. (2008). Evaluation of the energy efficiency commitment 2005-08. Report to the DECC. Wantage: Eoin Lees Energy.

Luchs, M., Naylor, R. W., Rose, R. L., Catlin, J. R., Gau, R., Kapitan, S., Mish, J., Ozanne, L., Phipps, M., Simpson, B., Subrahmanyan, S., and Weaver, T. (2011). Toward a sustainable marketplace: expanding options and benefits for consumers. Management and Organizational Studies Publications 6. [online] Available at: http://ir.lib.uwo. ca/mospub/6 [accessed 05/03/2019].

Lutzenhiser, L. (1992). A cultural model of household energy consumption. Energy, 17, 47-60.

Madsen, L. V. (2017). The comfortable home and energy consumption. Housing, Theory and Society, 35, 1-24.

Mallett, S. (2004). Understanding home: a critical review of the literature. The Sociological Review, 52, 62-89.

Morse, J., \& Richards, L. (2002). ReadMe first for a user's guide to qualitative methods. California: Sage Publications.

Mullaly, C. (1998). Home energy use behaviour: a necessary component of successful local government home energy conservation (LGHEC) programs. Energy Policy, 26, 1041-1052.

Nejat, P., Jomehzadeh, F., Taheri, M. M., Gohari, M., \& Majid, M. Z. A. (2015). A global review of energy consumption, $\mathrm{CO}_{2}$ emissions and policy in the residential sector (with an overview of the top ten $\mathrm{CO}_{2}$ emitting countries). Renewable and Sustainable Energy Reviews, 43, 843-862.

O'Brien, L. (2012). Global environmental change III: closing the gap between knowledge and action. Progress in Human Geography, 37, 587-596.

OECD (2013). OECD framework for statistics on the distribution of household income, consumption and wealth. OECD publishing. [online] Available at: http://www.keepeek. c o m / D i g i t a 1 - A s s e t Management/oecd/economics/framework-for-statistics-on- 
the-distribution-of-household-income-consumption-andwealth_9789264194830-en\#.WQNn-02M270\#page3 [accessed 04/02/2019].

ONS (2006). The effects of taxes and benefits on household income, 2004/05. Excel sheet. London: Office for Statistics. [online] Available at: http://www.ons.gov.uk/ peoplepopulationandcommunity/personalandhousehold finances/incomeandwealth/bulletins/theeffectsoftaxesand benefitsonhouseholdincome/2015-06-29 [accessed 28/04 /2017].

Pettifor, H., Wilson, C., \& Chryssochoidis, G. (2015). The appeal of the green deal: empirical evidence for the influence of energy efficiency policy on renovating homeowners. Energy Policy, 79, 161-176.

Pye, S., Li, F. G. N., Price, J., and Fais, B. (2017). Achieving netzero emissions through the reframing of UK national targets in the post-Paris Agreement era. Nature energy 2. Article number 17024.

Reckwitz, A. (2002). Toward a theory of social practices: a development in culturalist theorizing. European Journal of Social Theory, 5, 243-263.

Rinkinen, J., \& Jalas, M. (2017). Moving home: houses, new occupants and the formation of heating practices. Building Research and Information, 45, 293-302.

Sahakian, M., \& Wilhite, H. (2014). Making practice theory practicable: towards more sustainable forms of consumption. Journal of Consumer Culture, 14, 25-44.

Shove, E. (2010). Beyond the ABC: Climate change policy and theories of social change. Environment and Planning A, 42, 1273-1285.

Shove, E. (2017). What is wrong with energy efficiency? Building Research \& Information, 0, 1-11.

Shove, E., \& Pantzar, M. (2005). Consumers, producers and practices: understanding the invention and reinvention of Nordic Walking. Journal of Consumer Culture, 5, 43-64.

Shove, E., Pantzar, M., \& Watson, M. (2012). The dynamics of social practice: everyday life and how it changes. London: Sage.

Skudder, H., Druckman, J., Cole, J., Mclnnes, A., Brunton-Smith, I., \& Ansaloni, G. P. (2016). Addressing the carbon-crime blind spot: a carbon footprint approach. Journal of Industrial Ecology, 21, 829-843.

Sorrell, S., \& Dimitropoulos, J. (2008). The rebound effect: microeconomic definitions, limitations and extensions. Ecological Economics, 65, 636-649.

Southerton, D. (2013). Habits, routines and temporalities of consumption: from individual behaviours to the reproduction of everyday practices. Time \& Society, 22, 335-355.
Stern, P. (2000). Toward a coherent theory of environmentally significant behaviour. Journal of Social Issues, 56, 407-424.

Stoll, P., Brandt, N., \& Nordström, L. (2014). Including dynamic $\mathrm{CO}_{2}$ intensity with demand response. Energy Policy, 65, 490-500.

Strengers, Y. (2008). Comfort expectations: The impact of demand-management strategies in Australia. Building Research \& Information, 36, 381-391.

Strengers, Y., \& Maller, C. (2011). Integrating health, housing and energy policies: Social practices of cooling. Building Research \& Information, 39, 154-168.

The Electricity and Gas (Energy Companies Obligation) (Amendment) Order 2014. Statutory instruments Number 1131. London: HMSO.

Touval, A. (2017). Airbnb. In. Touval, A., An anthropological study of hospitality: the innkeeper and the guest. Cham: Springer International Publishing.

United Nations (2015). Paris Agreement. [online] Available at: h t t p s:// unf c c c.int/files/essential background/convention/application/pdf/english_paris_agreement.pdf [accessed 04/02/2019].

Vlasova, L., \& Gram-Hanssen, K. (2014). Incorporating inhabitants' everyday practices into domestic retrofits. Building Research \& Information, 42, 512-524.

Warde, A. (2005). Consumption and theories of practice. Journal of Consumer Culture, 5, 131-153.

Warde, A. (2014). After taste: culture, consumption and theories of practice. Journal of Consumer Culture, 14, 279-303.

Warriner, G. K., McDougall, G. H., \& Claxton, J. D. (1984). Any data or none at all? Living with inaccuracies in self-reports of residential energy consumption. Environment and Behaviour, 16, 503-526.

Wilhite, H., and Ling, R. (1992). The person behind the meter: an ethnographic analysis of residential energy consumption in Oslo. Paper presented at the Proceedings of the ACEEE 1992 Summer Study on Energy Efficiency in Buildings, Washington, D.C.

Wilhite, H., Nakagami, H., Masuda, T., Yamaga, Y., \& Haneda, H. (1996). A cross-cultural analysis of household energy use behaviour in Japan and Norway. Energy Policy, 24, 795803.

Wilson, C., Hargreaves, T., \& Hauxwell-Baldwin, R. (2017). Benefits and risks of smart home technologies. Energy Policy, 103, 72-83.

Publisher's note Springer Nature remains neutral with regard to jurisdictional claims in published maps and institutional affiliations. 